\title{
A Descriptive Study of Infrastructure Capabilities for Digital Records Preservation among Selected Public Institutions in Tanzania
}

\author{
Jacquiline Daniel \\ Local Government Training Institute, Hombolo, Dodoma, Tanzania \\ Email: jacquiline.daniel@yahoo.com \\ Faraja Ndumbaro \\ Information Studies Programme, University of Dar es Salaam, Tanzania \\ Email: ndumbaro.faraja@udsm.ac.tz
}

\begin{abstract}
In this paper, results of a descriptive study on institutional infrastructure capabilities for preserving digital records are presented. The study was carried out at Records and Archives Management Department (RAMD) and Registration, Insolvency and Trusteeship Agency (RITA). Informing the study, two research questions were in consideration: How capable are RAMD and RITA in terms of infrastructure capabilities for preserving digital records? What infrastructural challenges RAMD and RITA contend in preserving digital records? A multiple case studies and mixed research approaches were used. The study population comprised of 290 staff members, 75 from RAMD and 215 from RITA. A sample of 74 middle and lower level officers and 13 senior staff were purposively and randomly selected respectively. Data were collected through key informant's face to face interview and questionnaire. Results indicate that RAMD and RITA have relatively advanced infrastructure capabilities. Notably, shortage of fund, inadequate hardware, insufficient IT support, inadequate management commitment towards enhancement of infrastructure capabilities are among the digital records preservation challenges faced by RAMD and RITA. Based on the results, would seem to suggest that RAMD and RITA are at transitional capabilities because the available infrastructures are advance but inadequate to effectively support digital records preservation initiatives.
\end{abstract}

Keywords: Digital preservation, digital records, infrastructure capabilities, preservation capabilities, RITA, RAMD

https://dx.doi.org/10.4314/udslj.v16i2.10

\section{Introduction}

Digital records preservation is a strategic and continuous process of keeping and maintaining the accessibility, authenticity, and longevity of digital records. It involves the identification of records to be preserved and long term storage and protection of the records against myriad threats (Anyaoku \& Echedom, 2018). Within the context of an institution, digital records preservation capability is conceptualized as preparations and capacity to have a long term and successful 
programme that ensures digital records are preserved for continuous availability, accessibility, and usability (Katuu, 2019).

Organizations' capability to handle digital records determines the current and future availability of records. Institutional creation and use of digital records do not guarantee that the records will be well preserved to survive for a long period of time (Nkala, Ngulube \& Mangena, 2012). Effective management of digital records depends on how well prepared and capable an institution is to ensure long term preservation. Digital record preservation capabilities may include transitional capabilities where an institution is at initial stage towards a digital records preservation programme (Dollar \& Ashley, 2015). Optimum digital records preservation capability is the highest level where an institution has met all the requirements for digital records preservation (Dollar \& Ashley, 2015).

One of the elements of digital preservation capabilities is infrastructure capabilities. Notably, digital records infrastructure preservation capabilities comprise of technical components that enable digital preservation (Dollar \& Ashley 2015). The other component of digital records preservation infrastructure is digital preservation network capabilities which includes stakeholders in preservation, policies and practices Svärd (2017). Within the context of this study, the term infrastructure capability has been narrowly used to include capabilities in terms of hardware and software, financial capabilities, preservation strategies and preservation programme effectiveness.

Records and Archive Management Department (RAMD), previously known as Tanzania National Archive (TNA) is the government department responsible for the administration and management of public records and archives in their entire life cycle (Kamatula \& Kemoni, 2018). The department also advises the government on matters related to management of archives and records, adherence to the best records and archives management practices, and preservation of national heritage (Kamatula \& Kemoni, 2018). RITA is an executive agency established in 2006 under the Ministry of Justice and Constitutional Affairs. It aims at ensuring justice and enhancing national development through effective and efficient management of information on key events including insolvency and trusteeship services, (RITA, 2021). To achieve its mission, RITA needs to adhere to best records and archives management practices. Both RAMD and RITA have embraced Information and Communication Technologies (ICTs) into their service provisions. This is part of institutional implementation of e-governance.

Effective digital records preservation largely depends on how the available infrastructures are capable of enhancing availability and accessibility of authentic, reliable and accurate digital records. Hence, an institution must determine its capabilities in terms of hardware, software, network and preservation strategies for effective digital records preservation. Therefore, this has generated the researchers'

A descriptive Study of Infrastructure Capabilities for Digital Records Preservation among Selected Public Institutions in Tanzania

Jacquiline Daniel \& Faraja Ndumbaro 
interest to assess institutional infrastructure capabilities for digital records preservation in public institutions to determine their capability levels. Likewise, there is little empirical evidence on digital preservation capabilities of public institutions in Tanzania, RAMD and RITA in particular. There is paucity of empirical studies on digital records preservation infrastructure capabilities (Wato, 2006; Kamatula \& Kemoni, 2018; Asongwa, 2012). Therefore, the need for assessing digital records preservation infrastructure capabilities of public institutions to identify levels of infrastructure capabilities and associated challenges was imperative. Consequently, the purpose of this study was to assess digital records preservation infrastructure capabilities at RAMD and RITA, with focus on financial, hardware, software capabilities and preservation strategies. The study was guided by two research questions: How capable are RAMD and RITA in terms of infrastructure capabilities for preserving digital records? And What infrastructural challenges RAMD and RITA contend in preserving digital records?

\section{Related literature}

\section{Digital Preservation Infrastructure Capabilities}

Digital preservation capabilities include various attributes that an institution needs to have in order to ensure long term preservation of digital records. To achieve optimum capabilities, institutions must have robust infrastructures to enhance optimum digital records preservation. Institutions' infrastructure capabilities are measured by looking at various factors including financial resource capabilities, presence and use of preservation programme, effectiveness of preservation strategies, technologies in use, and level of collaboration among different stakeholders (Dollar \& Ashley 2015). Digital records preservation infrastructure capability is determined by organization's capacity to deploy preservation technologies and having digital repositories that are capable of maintaining digital records preservation software and ensuring sustainable and continuous availability and usability of digital records (Ross \& Hedstrom 2005).

Technology used in the creation, capture, and use of digital records has been considered as one of the parameters for determining how robust is digital records preservation infrastructure (Ross \& Hedstrom, 2005; Dollar \& Ashley 2015). Preservation infrastructure capability is also determined by the presence of a digital repository designed as a digital records centre able to receive, accept, share and transfer digital records with archival value from different units (Decman \& Vintar, 2013, Mannheimer \& Cote, 2016). The use of modern technologies that comply with International standards such as ISO 20652, ISO 14721, and ISO 18492 is essential in reaching optimal preservation capabilities (Decman \& Vintar, 2013). 
It is worth to note that digital record preservation capabilities have to be maintained from time to time. This is underscored by (Purcell, 2019) who calls for the need to review, evaluate and revaluate preservation technologies on regular basis. Similarly, adherence to technical standards such as Preservation Metadata Implementation Strategies (PREMIS) and Metadata Encoding and Transmission Standard (METS) are preeminent factors for an institution to attain optimal preservation capabilities (Digital Preservation Coalition, 2015).

There is considerable amount of literature on digital records preservation (Groenwald \& Breytenbach 2011, Dressler, 2016; Svärd, 2017; Adu \& Ngulube, 2017). While much has been written on preservation of digital and electronic records (Komba, Nawe \& Manda, 2017; Magama, 2018; Matlala, 2019), there is little research attention on digital records preservation infrastructure capabilities. Masenya and Ngulube (2019) noted that digital records preservation requires adequate infrastructure including accurate strategies, technologies and other resources useful for ensuring long term survival of the digital records. Houghton (2016) noted that digital records preservation is affected by technological dynamics and infrastructure vulnerability hence it involves preservation of past and future technology.

\section{Digital Records Infrastructure Preservation Challenges}

For an institution to reach optimum preservation capabilities must overcome number of challenges. Evidence form the literature suggest that digital records preservation is an expensive undertaking and most institutions, particularly in Africa do not have enough funds to invest in (Yadav, 2016). Houghton (2016) also noted that digital records preservation is costful as it requires enough fund to enhance proper digitization and continuous maintenance of the infrastructure. Oehlerts and Liu (2013) noted that digital records preservation is challenged by financial limited resources.

Apart from that, available infrastructures are inadequate and frustrating as evidenced by the unstable power supply which constantly causes equipment failure and damage (Yadav, 2016). Similarly, Masenya and Ngulube (2019) pointed that digital preservation is challenged by inadequate resources and technological infrastructure. Consequently, it is impossible to have technological environment that is suitable and favourable for digital records preservation activities (Yadav, 2016).

Anyaoku and Echedom (2018) pointed out some digital records preservation infrastructure challenges including technological changes, media instability, shortage of funds, incompetence in managing digital repositories and little control over digital records. The same was noted by Houghton (2016) that digital records preservation infrastructures become obsolesce. As the technologies change over time affect the digital information because some new versions of software do not support digital A descriptive Study of Infrastructure Capabilities for Digital Records Preservation among Selected Public Institutions in Tanzania

Jacquiline Daniel \& Faraja Ndumbaro 
records that were created in other versions. Consequently, accessibility become challenging due to hardware and software incompatibilities.

Savard (2017) found that many archival institutions have no digital repositories to support capturing, management and preservation of digital records. On the same note, Mapulanga (2013) noted that viruses attack on various databases as one of the challenges for digital records preservation. The viruses potentially affect both the software, hardware and digital information (Mapulanga, 2013). Institutions also face challenges on how to enhance access to digital records while ensuring digital records and infrastructures remained secured (Houghton 2016). In some cases, studies have reported that lack of comprehensive preservation strategies as the setback in preservation initiatives (Houghton 2016). There is no single preservation strategy that fits all type of records because the preservation strategies depend on availability of resources, organization requirements and the nature of records, (Houghton 2016). Each strategy depends on organization requirement, types of records and available resources (Houghton 2016).

\section{Theoretical Framework}

This study was guided by the Digital Preservation Stool Model. This model was developed by Anne Kenney and Nancy McGovern for presentation at the digital preservation workshop conducted by Cornell University in 2003.

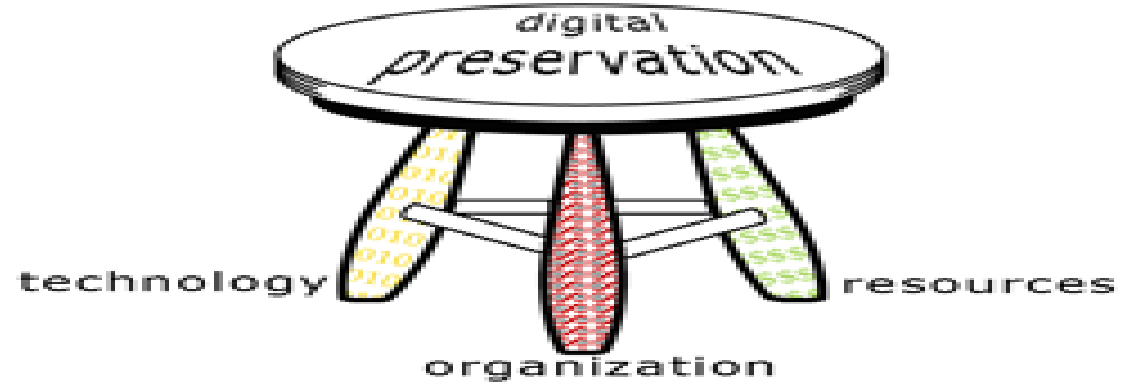

Figure 1: $\quad$ Digital preservation stool model

Source: Cornell University (2003)

According to this model, digital records preservation depends on three components, namely, technology, institution, and resources. Each component (leg) of the stool must be maintained to avoid the collapse of a digital preservation programme (McGovern, 2007; Manson, 2017). In the three-legged stool model for digital preservation, an institutional infrastructure's leg includes policies, procedures, staffing and objectives (Cornell University 2003). The technology leg, on the other hand, includes software, hardware and other tools for digital preservation while the 
resource leg includes initial and continuous availability of financial resources. This model is useful for any institution intending to establishing a digital records preservation programme and assess its digital records preservation capabilities. In the context of this study, the model has been used in assessing digital records preservation infrastructure capabilities. Particularly, the model provides a framework for assessing how institutional infrastructures support digital records preservation. Also, the model has been also used to guide assessment of challenges facing RAMD and RITA with regards to digital records preservation.

\section{Methods and Procedures}

This study was based on a multiple case studies with a mix qualitative and quantitative approaches. The study was conducted at RAMD and RITA. These institutions are based in Dar es Salaam, Tanzania. RAMD has been given a legal mandate of ensuring long term preservation of all public records hence appraising its capabilities is essential. RITA was selected because of its mission is to ensure justice through effective management of information for national development. Population of this study included 290 staff; 75 from RAMD and 215 from RITA. These included senior officers, middle level staff and lower level staff. A total of 74 middle and lower level officers were selected using simple random sampling method. Purposive sampling method was used to select 13 senior managers. In total 87 respondents were involved in the study.

Self-administered questionnaire was administered to 74 middle and lower level staff. Quantitative data collected from questionnaires were analysed quantitatively using SPSS. Different levels of analysis were employed such as conceptual, relational and descriptive statistical methods. Face to face interview was conducted to $13 \mathrm{key}$ informants from RAMD and RITA. Interview records were transcribed, coded and analysed thematically. Themes emerged from the interviews, were orgarnised into related clusters. Quantitative results are presented using tables, figures while qualitative results are presented in narrative form supported by interview extracts. Qualitative results are presented in form on interview extracts. The researchers adhered to ethical requirements by ensuring honesty, integrity, and confidentiality where there was no disclosure of individual information and identities at all stages of data collection, analysis, interpretations and findings reporting. The researchers also avoided asking questions that could lead to any physical or psychological harm. The researchers also sought an informed consent from respondents and got permission to collect data hence latter of approval was obtained from RITA and RAMD.

A descriptive Study of Infrastructure Capabilities for Digital Records Preservation among Selected Public Institutions in Tanzania

Jacquiline Daniel \& Faraja Ndumbaro 


\section{Results}

This section provides the findings on RAMD and RITA architecture capabilities in supporting digital records preservation.

\section{Demographic Characteristics of Respondents}

Respondents were asked about their demographic characteristics. The findings revealed that majority of respondents were aged between 31 to 45 years. In terms of education and working experiences it was revealed that majority of respondents have at least bachelor degrees with over six years of working experience.

Table 1. Demographic Information

\begin{tabular}{|c|c|c|}
\hline Institutional affiliation & Frequency & Percentage \\
\hline RAMD & 15 & 20.3 \\
\hline RITA & 59 & 79.7 \\
\hline Sex & Frequency & Percentage \\
\hline Male & 32 & 43 \\
\hline Female & 42 & 57 \\
\hline Education qualification & Frequency & Percentage \\
\hline Diploma & 8 & 10.8 \\
\hline Bachelor degree & 47 & 63.5 \\
\hline Masters & 19 & 25.7 \\
\hline Respondents age & Frequency & Percentage \\
\hline Below 30 years & 12 & 16.2 \\
\hline 31 to 35 years & 24 & 32.4 \\
\hline 36 to 40 years & 22 & 29.7 \\
\hline 41 to 45 years & 14 & 18.9 \\
\hline 46 to 50 years & 2 & 2.7 \\
\hline Working experience & Frequency & Percentage \\
\hline Less than 2 years & 8 & 10.8 \\
\hline 2 to 5 years & 15 & 20.3 \\
\hline 6 to 10 years & 31 & 41.9 \\
\hline More than 10 years & 20 & 27 \\
\hline Occupation & Frequency & Percent \\
\hline Human resource officer & 6 & 8.1 \\
\hline Records officer & 18 & 24.3 \\
\hline Librarian & 3 & 4.1 \\
\hline Accountant & 3 & 4.1 \\
\hline Registration officer & 15 & 20.3 \\
\hline ICT officer & 9 & 12.2 \\
\hline Auditor & 3 & 4.1 \\
\hline Legal officer & 11 & 14.9 \\
\hline
\end{tabular}




\begin{tabular}{lll} 
Planning officer & 3 & 4.1 \\
Procurement officer & 3 & 4.1 \\
\hline
\end{tabular}

Source: Field data, 2020

\section{Digital Records Preservation Infrastructural Capabilities}

The following aspects of digital preservation infrastructure capabilities were assessed: financial capabilities, availability digital records preservation program and strategies/approaches, technology capabilities, collaboration and digital records preservation challenges. The results are presented here under.

\section{Digital Records Preservation Financial Resources}

Having a budget specifically for digital records preservation matters is an indication for robust institutional preservation capabilities. Most respondents indicated that there was no special budget allocated for digital records preservation while few indicated that the budget existed but was not adequate.

Table 2. Financial Capabilities

\begin{tabular}{lcc}
\hline \multicolumn{3}{c}{ Special Budget for Digital Records Preservation $\mathbf{n = 7 4}$} \\
\hline Response & Frequency & Percentage \\
Allocated & 21 & 29 \\
Not allocated & 38 & 51 \\
I do not know & 15 & 20 \\
\multicolumn{1}{c}{ Adequacy of Digital Preservation } & Budget $\mathbf{n = 2 1}$ \\
Responses & Frequency & Percentage \\
Very adequate & 1 & 4.7 \\
Adequate & 5 & 23.8 \\
Not adequate & 15 & 71.4 \\
\hline
\end{tabular}

Source: Field data, 2020

The fact that others indicated the availability of such budgets while others said the budgets did not exist indicates the level of staff awareness on the matter or even their involvement in budget planning as well as digital records preservation. Consistent with these observations, it was also confirmed by key informants that the institutions do not have dedicated budget for digital records preservation.

We don't have a special budget for digital records preservation and some preservation plans have been left pending due to shortage of funds. (RITA 5)

A descriptive Study of Infrastructure Capabilities for Digital Records Preservation among Selected Public Institutions in Tanzania

Jacquiline Daniel \& Faraja Ndumbaro 
With regards to adequacy of the budget for preservation, it was reported in one of the interview that the budget does not meet all preservation needs:

We don't have other sources of funds. That is why we only depend on general government budget which is not enough to meet preservation requirement. As a result, our long-term plans are affected (RAMD 4)

\section{Digital Records Preservation Strategies}

The respondents were asked to indicate if their organizations had established a digital records preservation programme and the approach that they would consider when developing or redesigning their digital records preservation programme. From the results, majority indicated that the programme is not established. Furthermore, 18(24.3\%) respondents mentioned in-house digital preservation approach while $54(73 \%)$ opted for partnership with other institutions, and $2(3 \%)$ opted for outsourcing from other institutions.

Table 3: Digital Records Preservation Strategies

Establishment of digital records preservation programme $n=74$

\begin{tabular}{lll}
\hline Response & frequency & percentage \\
programme established & 19 & 26 \\
not established & 44 & 59 \\
I do not know & 11 & 15 \\
\multicolumn{1}{c}{ Approach for developing digital records preservation programme (n=74) } \\
Response & Frequency & Percentage \\
In house approach & 18 & 24.3 \\
Partnership with other organizations & 54 & 73 \\
Outsourcing from other organizations & 2 & 3 \\
\hline
\end{tabular}

\section{Source: Field data, 2020}

Through interviews, it has been further noted that there are no plans in place of establishing digital records preservation programmes in the near future. The findings have further revealed that most respondents prefer partnering with other institutions in preservation of their digital records through sharing of infrastructure, skills and expertise. Strong preference of this approach was confirmed through findings from interviews.

Through partnership, we are able to share infrastructure like servers and storage centre with the government data centre (RITA 6) 
Another respondent had this to say:

We preserve records that are created by different public offices; we have the mandate to oversee records management practices in all government offices so we have to partner with them in preserving digital records (RAMD 5).

\section{Technology Capabilities}

The results on technology preservation capabilities comprise of digital records preservation system capabilities, hardware and software capabilities.

\section{Digital Records Preservation System Capabilities}

Presence on digital records preservation system is an indicator of institutional capabilities on preservation. As indicated in table 4, trusted digital repository system is the system in use at RAMD, while the civil registration system is used at RITA Table 4 summarises these findings.

Table 4: Type of system used for digital records preservation $(n=74)$

\begin{tabular}{lccccc}
\hline System & \multicolumn{2}{c}{ RAMD } & \multicolumn{2}{c}{ RITA } \\
& & Frequency & Percent & Frequency & Percent \\
\hline Trusted digital & repository & 10 & 66.6 & 0 & 0 \\
system & & 1 & 6.6 & 2 & \\
Content management system & 0 & 0 & 1 & 3.3 \\
Star topology network & 0 & 0 & 46 & 77.9 \\
Civil registration system & 4 & 26.6 & 10 & 16 \\
I do not know & & & & & \\
\hline
\end{tabular}

Source: Field data, 2020

Globally, various systems are used to preserve digital records. However, through interviews, it was learned that only two systems were in use. For instance, the following statements were made by interviewees:

We have our own system for digital records preservation which is called trusted digital repository system (RAMD3)

We have our system known as civil registration system which is used to preserve birth and death records (RITA 8).

A descriptive Study of Infrastructure Capabilities for Digital Records Preservation among Selected Public Institutions in Tanzania

Jacquiline Daniel \& Faraja Ndumbaro 
Respondents were asked if the digital records preservation systems used at their workplaces had active servers for backups, the specific time of upgrading the systems, system compliance with standards and its security level in protecting digital records. The results obtained indicate that majority $(58,78 \%)$ agreed that the systems have the said servers. In contrast, 16(22\%) respondents did not know if these servers were available on the systems in use.

Table 5: Digital Records Preservation System Capabilities

\begin{tabular}{lll}
\hline $\begin{array}{l}\text { Availability of active servers for backups }(\mathbf{n = 7 4}) \\
\text { Response }\end{array}$ & Frequency & Percentage \\
\hline Servers with backups are available & 58 & 78 \\
I do not know & 16 & 22 \\
System upgrading (n=60) & & \\
Response & Frequency & Percentage \\
Every year & 7 & 11.6 \\
After two years & 4 & 6.6 \\
After three years & 3 & 5 \\
Whenever there is new updates & 46 & 76.6 \\
System compliance (n=60) & & \\
Response & Frequency & Percentage \\
System compliance & 6 & 10 \\
I do not know & 54 & 90 \\
System security level in protecting digital records $(\mathbf{n}=\mathbf{6 0})$ & \\
Response & Frequency & Percentage \\
Highest security & 35 & 47.3 \\
High security & 25 & 33.8 \\
\hline
\end{tabular}

Source: Field data, 2020

Also $7(11.6 \%)$ respondents indicated that upgrading is done every year, $4(6.61 \%)$ said it is done after every two years, 3(5\%) said after every three years, and $46(76.6 \%)$ said upgrading was done whenever there were new changes. On compliance issue 54(73\%) respondents said the systems comply with preservation requirements and standards while $20(27 \%$ ) did not know if the systems comply or do not comply with the requirements and standards. Furthermore, 35(47.3\%) respondents indicated that the systems have highest level of security while 25(33.8\%) indicated high level of security.

Similarly, interviews show that both RAMD and RITA have active servers with backups which guarantee survival of their records. It was further noted that there is no formal schedule for upgrading the systems. Evidently, the systems appear to be upgraded when there are changes and updates of which it is the responsibility of IT specialists to learn about any changes and updates available and take actions. 
Our institution has primary and secondary servers located in different places as backups in case disasters strike. We have servers in Dodoma and in Dar es Salaam (RAMD 1)

We have one server here and others that are located in different areas but we also use servers from government data centre to back up our records" (RITA 6)

Results further indicated that the systems have met the required standards including high level of security. It was revealed during interviews that the systems have active metadata, various security levels, strong passwords, and monthly password change requirements. It was also noted that the systems have been encrypted to safeguard records. There is also use of firewalls and other security measures to protect digital records. The following interview extracts illustrate more:

Our system is updated when there are new updates, no specific time for upgrading (RITA 2)

IT staff upgrades the system when there are updates or any changes (RAMD 4)

This system was designed and developed by experts from inside and outside the country with the support of government, World Bank and other stakeholders in adherence to international and national standards (RAMD 5)

Regarding security, we are very sure the records are safe. We have implemented all the required measures like passwords, access classification and establishment of firewalls to secure digital records (RITA 7)

\section{Hardware/Equipment Capabilities}

The study also focuses on capabilities in terms of digital records preservation hardware sufficiency, conditions and replacement rate. These findings are summarized in Table 6:

Table 6: Hardware capabilities $(n=74)$

\begin{tabular}{lcc}
\hline Hardware & Frequency & Percent \\
\hline Sufficient & 25 & 33.8 \\
\hline
\end{tabular}

A descriptive Study of Infrastructure Capabilities for Digital Records Preservation among Selected Public Institutions in Tanzania

Jacquiline Daniel \& Faraja Ndumbaro 
Not sufficient

I do not know

Hardware condition

Very good

Good

Poor

I do not know

Hardware replacement

Agree

Disagree

I do not know

Hardware replacement time

After 3 years

After 5 years

When they collapse

I do not know
44

5

Frequency

14

54

2

4

Frequency

34

24

16

Frequency

3

8

47

16
59.5

6.8

\section{Percent}

18.9

2.7

5.4

Percent

45.9

32.4

21.6

Percent

4.1

10.8

63.5

21.6

\section{Source: Field data, 2020}

Results show that the institutions do not have sufficient hardware/equipment for digital records preservation. Despite having insufficient hardware for preserving digital records, on the condition of the equipment, it is evident from the results that most of the hardware for supporting digital preservation are in good condition. The results obtained on hardware replacement indicate that relatively most of respondents (47\%) had the view that the hardware are not replaced on regular basis. The institutions in most cases stay with the preservation hardware for more than three years. The results on hardware insufficiency obtained from questionnaire survey correspond with those from interview:

The available equipment and hardware are not enough. For example, staff dealing with digital records preservation have to share the available computers to execute their duties. Apart from that, scanners are few (RAMD 4).

\section{Digital Repository}

Institutional digital repository ensures among other things effective preservation of institutional digital records. The results on availability of digital repository are illustrated in table 7 :

Table 7: Digital repository 


\begin{tabular}{|c|c|c|}
\hline \multicolumn{3}{|c|}{ Existence of Digital Repository } \\
\hline Response & Frequency & percentage \\
\hline Digital repository exists & 55 & 74 \\
\hline Digital repository do not exist & 5 & 7 \\
\hline I do not know & 14 & 19 \\
\hline \multicolumn{3}{|c|}{ Digital Repository's Records Preservation Period } \\
\hline Repository capability & Frequency & Percent \\
\hline 1 to 5 years & 5 & 9 \\
\hline 5 to 10 years & 4 & 7.2 \\
\hline 10 to 15 years & 8 & 14.5 \\
\hline More than 15 years & 38 & 69.09 \\
\hline
\end{tabular}

\section{Source: Field data, 2020}

The findings, show that majority of $55(74 \%)$ respondents said their institution had a digital repository. Respondents were generally confident that their repositories are capable of preserving institutional digital records for a period of more than 15 years. Similarly, through interviews, it was noted that RAMD and RITA have strong and up to date digital repositories located in different areas that are capable of receiving, accepting, sharing and transferring digital records from different units. They have very high security capable of protecting and ensuring long term survival of digital records. Additionally, RAMD and RITA also backup their digital records at the national digital repository known as data centre. For instance, one respondent was quoted saying:

Our repository has active and strong metadata and enhanced security. It can preserve records for more than fifty years. (RAMD 3)

\section{Digital records Preservation Collaboration}

Respondents were asked whether their institutions collaborate with other institutions or not. The study also sought to ascertain potential areas for future collaboration in digital records preservations. Table 8 summarizes the findings.

Table 8: Digital records preservation collaboration

\begin{tabular}{lcc}
\hline \multicolumn{2}{c}{ Digital records preservation collaboration $(\mathbf{n = 7 4})$} \\
Response & Frequency & percentage \\
\hline There is collaboration & 63 & 85 \\
There is no collaboration & 11 & 15 \\
& Areas of collaboration $(\mathbf{n}=\mathbf{7 4})$ & \\
Areas of collaboration & Frequency & Percent \\
Infrastructure & 23 & 31 \\
\hline
\end{tabular}

A descriptive Study of Infrastructure Capabilities for Digital Records Preservation among Selected Public Institutions in Tanzania

Jacquiline Daniel \& Faraja Ndumbaro 


\begin{tabular}{lcc}
\hline Human resources & 28 & 38 \\
Information sharing & 34 & 46 \\
No need for collaboration & 5 & 7
\end{tabular}

Source: Field data, 2020

The findings have revealed that both RAMD and RITA collaborate with other institutions. In fact, RAMD preserves records with long-term value created by public offices in addition to having the mandate to oversee records management practices in all public offices. The records that are created by RITA, including those to do with births and deaths, are also used by other institutions in performing their duties. Through interviews, it was noted that RAMD and RITA have benefited from collaboration in number of ways as heard from respondents who made the following comments:

Collaboration has helped us to minimize costs in terms of infrastructure and hiring of technical experts. (RITA 8)

Yes, we collaborate with many institutions through sharing information, resources, and experience. These institutions include IDA, Data centre, migration office, national museum and national library. (RAMD 2)

\section{Digital Records Preservation Challenges}

A list of challenges was included from which respondents were asked to identify similar challenges that they encounter in their institutions. The results of the challenges contended by respective institutions are summarized in Table 9:

Table 9: Digital records preservation challenges at RAMD and RITA $(n=74)$

\begin{tabular}{|c|c|c|c|c|}
\hline \multirow[b]{2}{*}{ Challenges } & \multicolumn{2}{|c|}{ RAMD } & \multicolumn{2}{|c|}{ RITA } \\
\hline & Frequency & Percent & Frequency & Percen \\
\hline Insufficient funds & 11 & 73.3 & 23 & 38.9 \\
\hline shortage of hardware & 4 & 26.6 & 20 & 33.8 \\
\hline $\begin{array}{l}\text { Insufficient } \quad \text { IT } \\
\text { support }\end{array}$ & 2 & 13.3 & 5 & 8.4 \\
\hline $\begin{array}{lr}\text { Inadequate } & \\
\text { management } & \text { support } \\
\text { awareness } & \text { and } \\
\text { commitment } & \end{array}$ & 3 & 20 & 21 & 35.5 \\
\hline $\begin{array}{l}\text { Lack of expertise and } \\
\text { experience }\end{array}$ & 8 & 53.3 & 10 & 16.9 \\
\hline
\end{tabular}


Source: Field data, 2020

As Table 9 indicates, shortage of funds in the dominant challenge that hinders effective and continuous digital records preservation. During interviews, it was learned that RAMD faces shortage of facilities including computers, scanners, and other infrastructures due to limited budget or shortage of fund.

To be honest, we do not have enough facilities for digital records preservation. We have so many records that need to be scanned but we have few scanners and this prolongs the digitization process. We also share computers because they are not enough for all staff members. (RAMD 5)

We can't afford to buy enough facilities because we are given little budget by the government that does not meet our needs. (RAMD 2)

\section{Discussion}

Digital records preservation is expensive and most institutions have insufficient fund to invest in digital records preservation. The results indicated that both RAMD and RITA have insufficient budgets for digital records preservation. The institutions depend on general budgets from the government in which digital records preservation issues are not given higher priority. Consequently, the funds allocated are not enough to meet all preservation requirements. This can also be attributed to institution's lack of alternative sources of funds which forces them to rely on an insufficient government budget. The findings are similar to Oehlerts and Liu (2013), who noted that digital records preservation is challenged by limited financial resources. Similarly, Yadav (2016) revealed that most institutions in Africa have insufficient funds to invest in digital records preservation infrastructures.

Results on digital records preservation strategies indicate that RAMD and RITA have not established preservation programmes for their digital records. Additionally, the institutions prefer partnership preservation approach. This is partly due to the fact that the nature and functions of RAMD and RITA foster partnership in many ways including information, infrastructure, and human resources sharing. As noted by Mannheimer and Cote (2016), having a digital records preservation programme enables even small institutions to meet digital records preservation needs and requirements. It is clear that without these programmes, it is difficult to see RAMD and RITA meeting preservation needs.

Trusted digital repository system and civil registration system were noted to be used at RAMD and RITA. It was also noted during interviews that the said A descriptive Study of Infrastructure Capabilities for Digital Records Preservation among Selected Public Institutions in Tanzania

Jacquiline Daniel \& Faraja Ndumbaro 
systems are capable of creating, receiving, keeping, and organizing records while also ensuring long term survival of records. The two systems are also capable of ingesting, sharing, and acquiring records from other institutions. Other systems that were mentioned, include, content management system and star topology network, Notably, these two systems are not used for digital records preservation. It was further noted that the systems used by RAMD and RITA (Trusted digital repository system and civil registration systems) are capable of ensuring effective preservation of digital records. The systems have active servers with backups, and they have met required standards including security standards through active metadata, strong passwords and other security levels. These findings are in line with Manson (2017) who pointed out that a capable institution must have secured servers and software that will ensure long term digital records preservation. Likewise, Groenwald and Breytenbach (2011) noted that digital records must be stored using active servers with backups and metadata.

Katuu (2019) recommended that digital preservation systems must comply with records management standards and practices especially International standards. These standards include ISO 20652, ISO 14721, and ISO 18492 and technical standards such as Preservation Metadata Implementation Strategies (PREMIS) and Metadata Encoding and Transmission Standard (METS). Institutions require a robust technology with maximum security to ensure that digital records are not attacked by hackers and viruses (Mapilanga 2013). It was further noted that RAMD and RITA appear to have taken enough precautions to protect their systems from hackers and viruses.

On hardware capabilities it was noted that both institutions are faced with inadequate hardware for digital records preservation. Consequently, staff are forced to share the available computers, scanners and other hardware in executing their preservation duties. The preservation stool model indicates that institutions must have robust hardware infrastructure for providing digital preservation services. Similarly, Groenwald and Breytenbach, (2011) noted that institutions must have enough hardware that are up to date and capable of supporting digital records preservation services. As such, it can be said that RAMD and RITA lack this capability because of the reported shortage of these hardware infrastructure which are also not updated and replaced on time. This may be associated with budget inadequacies and insufficient management support and commitment. In all, this state places digital records in danger of getting lost.

It was revealed that RAMD and RITA have well secured digital repositories with remote backup servers located in different places. The repositories are capable of protecting and preserving digital records for a long period of time of more than fifteen years. These findings echo those by Gladney (2009) who noted that digital records preservation capability is influenced by the presence of a trustworthy digital record repository. Such a repository is supposed to be capable of ensuring that digital 
records are secured, usable, understandable, accessible, and interpretable to users for as long as they are needed. Dollar \& Ashley (2015) articulated that digital repository with audit and certification capabilities is an indicator of advanced digital preservation capabilities. Similarly, Mannheimer and Cote (2016) argue that infrastructure capability is reflected by the presence of a digital repository that is able to receive, accept, share, and transfer digital records from different processes. Such repositories should also be able to appraise and transfer records with archival value to digital archival repositories.

The findings further revealed that both RAMD and RITA prefer and use collaborative strategy for preserving their digital records. Collaboration has also been used by RAMD and RITA as a digital records backup strategy which is useful in case of disaster. Through collaboration, the institutions are able to share experience, knowledge, and infrastructures while handling their preservation challenges through teamwork. Altman, et al., (2009) noted that collaboration is essential and beneficial as it enhances easiness and continuity of operations, triggers joint use of infrastructure and helps to minimise running costs. Dollar and Ashley (2015) indicates that collaboration provides chances to the participating stakeholders to learn from each other and use the lessons learnt to improve their digital preservation services. Therefore, the nature of records and functions of these institutions necessitate collaboration. Collaboration is a base for institutions to improve preservation capabilities. The same was noted by Mannheimer and Cote (2016) who posited that with collaboration, institutions can share services, knowledge, and expertise which help to solve problems of digital records preservation and enhance best practices. Information sharing is one of the ways these two institutions collaborate with others. For example, RITA and NIDA share birth and death records. Another area of collaboration recorded by this study is infrastructure. Both RAMD and RITA share infrastructure with other institutions including the Data Centre with which they share storage facilities including servers and digital repository.

The institutions contended with number of digital records infrastructure preservation challenges. These include shortage of fund and preservation hardware like computers and scanners. Since some records at RAMD and RITA are still in the digitization process hence the longer it takes to digitize records due to shortage of infrastructure the longer it will take to implement full digital records preservation. On the whole, this obviously slows efforts to effectively preserve digital records. On this, Yadav (2016), Perry (2014) and Gladney (2009) noted that many institutions do not have enough funds to invest in effective digital records preservation hence the inadequacy of preservation infrastructures. Poor managerial support was also noted as a challenge towards effective digital preservation and this might affect the establishment and implementation of digital records preservation programmes and

A descriptive Study of Infrastructure Capabilities for Digital Records Preservation among Selected Public Institutions in Tanzania

Jacquiline Daniel \& Faraja Ndumbaro 
strategies. Gbaje and Mohammed (2013) reported that lack institutional and managerial support is one of the challenges affecting digital records preservation initiatives. Likewise, Mutula (2014) noted the same challenge where the government is inadequately supporting digital preservation activities.

Various strategies were suggested by interviewees. These included the provision of digital records preservation training to all staff dealing with digital records, and records management training to ICT staff. This would help to decrease RAMD and RITA's reliance on ICT staff because of their computer skills while undermining skills and expertise from other staff members especially records management staff and archivists. Respondents also suggested that creativity in seeking funds through other means including outreach programmes and finding donors inside and outside the country was the other ways to go. The findings have also shown that institutional and national legal frameworks for digital records management and preservation are needed to ensure effective digital records preservation.

\section{Conclusions}

Having essential infrastructure capabilities for preserving institutional digital records is one of the requisite factors for effective digital record preservation. This study brings to a close that RAMD and RITA have relatively advanced infrastructures for digital records preservation in terms of robust software and the digital repository. On hardware capabilities, the study concludes that the available hardware are robust but not enough to meet the preservation needs as well as preservation staff because staff tends to share the computers and scanners.

\section{Recommendations}

The study recommends that the institutions should make efforts to ensure that all required infrastructures are up-to-date. This applies to computers, scanners and systems related tools. The institutions must have adequate budgets special for meeting all digital records preservation requirements and establish digital records preservation programme.

With regards to collaboration with other stakeholders in preserving digital records, the study recommends that the institutions should pay attention to and improve their collaboration levels. Each institution should strategically think of essential areas that need collaboration and choose the best partners to collaborate with in consideration of their goals, interests, and benefits. The study also recommends that the institutions should have digital records preservation strategies aiming to improve their preservation capabilities. Digital records preservation should be part of their management processes to enable them to conduct needs assessments, 
establish policies, allocate enough budgets, supervise the implementation of programmes, and have a control mechanism. Both prospective and retrospective approaches should be adopted as part of digital records preservation strategies for the institutions to be able to anticipate problems, and mitigate and deal with them by reversing and restoring.

To reach the optimum digital records preservation capabilities, the institutions must, establish institutional frameworks and various guidelines that will guide their preservation activities especially, digital records preservation policy, digital deposit policy, digital records retention and disposal schedule, and others. The national frameworks for records management, especially policies and acts should be reviewed and updated to respond to technological advancements and needs for digital records preservation.

\section{Study implications}

Understanding institutional capabilities in terms of available infrastructure is essential for any institution. Knowledge of institution's preservation infrastructure capabilities forms the basis for taking evidence-informed preservation measures. It is within this context, a need for the public organizations, institutions and agencies to conduct self-assessments on infrastructure capabilities is of paramount importance. This is essential in identifying the gap and establishing or adopting the preservation strategies to bridge the gaps. On professional aspect this study insists on investing in digital records preservation infrastructures and equipping records staff with adequate ICT skills and knowledge on how to effectively utilize the available infrastructure in preserving digital records and make fully use of collaboration potentials.

\section{References}

Adu, K.K, \&Ngulube, P. (2017). Key threats and challenges to the preservation of digital records of public institutions in Ghana. Journal of Information and Communication Society, 20(8),1127-1145.

Anyaoku, E.N, 7 Echedom, U.N. (2018). Digital preservation practices in university libraries: An investigation of institutional repositories in Africa. Digital Library Perspectives, 35(1),41-64.

Cornell University Library. (2003). Digital preservation management workshop. Retrieved from www.pworkshop.org.dpm-eng/eng index.html

Decman, M, \& Vintar, M. (2013). A possible solution for digital preservation in egovernment: a centralized repository within a cloud computing framework. ASLIB Proceeding 65(4),406-424.

A descriptive Study of Infrastructure Capabilities for Digital Records Preservation among Selected Public Institutions in Tanzania

Jacquiline Daniel \& Faraja Ndumbaro 
Digital Preservation Coalition. (2015). Digital Preservation Handbook, $2^{\text {nd }}$ Edition. Retrieved from http://handbook.dpconline.org/

Dollar, C, \& Ashley, L. (2015). Digital preservation capability maturity model. Retrieved from https://www.statearchivists.org/resource-center/resourcelibrary/digital-preservation-capability-maturity-model-dpcmm/

Dressler, V.A. (2016). The state of affairs with digital preservation at ARL member libraries: A survey and analysis of policy. Digital Library Perspective 33(2), 137-155.

Gbaje, E.S. (2011). Digital preservation strategies: A case study of Nigerian national information centers. IFLA Journal, 37(3),218-227.

Gladney, H.M. (2009). Long-term preservation of digital Records: Trustworthy digital objects. American Archivists, 72(2), 401-432.

Groenewald, R, Breytenbach, A. (2011). The use of metadata and preservation methods for continuous access to digital data. The Electronic Library, 29(2), 236-248.

Houghton B. (2016). Preservation challenges in the digital age. Dlib Magazine 22(7/8)

International Records Management Trust. (IRMT). (2011). Managing records as reliable evidence for ICT/ e-government and freedom of information; Tanzania Country Report.

Kamatula, G. \& Kemoni, H. (2018). A framework for e-records in support of egovernment implementation in the Tanzanian public service. ESARBICA Journal, 37(2018),68-88.

Katuu S. (2019). Diverse Applications and Transferability of Maturity Models. IGI Global

Kemoni, H. (2009). Management of electronic records: Review of empirical studies from the Eastern, Southern Africa Regional Branch of the International Council on Archives (ESARBICA) region. Records Management Journal, 19(3), 190-203.

Komba, S.C, Nawe, J \& Manda, P.A. (2017). Preservation and accessibility of audiovisual records in Tanzania's television broadcasting companies. University of Dar es Salaam Library Journal, 12(2),22-36.

Lor, P. (2005). Preserving African digital resources: Is there a role for repository libraries. Library Management, 26(12),63-72.

Mannheimar, S, \& Cote, C. (2016). Cultivate, access, advocate, implement and sustain a five point plan for successful digital preservation collaborations. Digital Library Perspectives, 33(2),100-116.

Manson, J.D. (2017). Getting started with digital collections: scaling to fit your institution; American library association. Journal of Electronic Resources Librarianship, 29(3),183-198. 
Mapulanga, P. (2013). Digitising library resources and building digital repositories in the University of Malawi Libraries. The Electronic Library, 31(5),635647.

Magama, B. (2018). Strategies for preservation of digital records in Masvingo province of Zimbabwe. Journal of the Eastern and Southern Africa Regional Branch of the International Council on Archives, 37 (2018), 18-37.

Matlala, E. (2016). Long-term preservation of digital records at the University of KwaZulu-Natal archives. Journal of The South African Society of Archivists, 52(2019), 95-109.

Masenya, T.M. \& Ngulube, P, (2019). Digital preservation practices in academic libraries in South Africa in the wake of the digital preservation. South African Journal of $\quad$ Information Management, 21(1):1-9.

McGovern, N.Y (2007). A Digital Decade: where have we been and where are we going in digital preservation; $R L G$ Diginews, 11(1).

Mutula, S.M. (2014). Status of digital heritage preservation management in Eastern Africa. The Electronic Library, 32(3),363-374.

Nkala, G.S. Ngulube, P. \& Mangena, S. (2012). E-records readiness at the National archives of Zimbabwe. Unisa Press, 30(2),108-116.

Oehlerts, B, \& Liu, S. (2013). Digital preservation strategies at Colorado State University Libraries. Library Management, 34(1/2),83-95.

Purcell, A.D. (2019). The digital archives handbook; a guide to creation, management and preservation. Rowman and Littlefield.

Ross, S, \& Hedstrom, M. (2005). Preservation research and sustainable digital libraries. International Journal on Digital Library, 5(4), 317-324.

Registration, Insolvency and Trusteeship Agency (RITA), (2021). www.rita.go.tz

Smallwood, R.F. (2013). Managing electronic records: methods, best practices, and technologies. Wiley Publishing.

Svärd, P. (2017). The woes of Swedish private archival institutions. Records Management Journal, 27(3),275-285.

Wato, R. (2006). E-records readiness in the ESARBICA region: Challenges and the way forward. ESARBICA Journal, 25(1), 52-63.

Yadav, D. (2016). Opportunities and challenges in creating digital archive and preservation: An overview. International Journal of Library Services, $6(2), 63-73$.

A descriptive Study of Infrastructure Capabilities for Digital Records Preservation among Selected Public Institutions in Tanzania

Jacquiline Daniel \& Faraja Ndumbaro 